\title{
Effects of Different Photoperiodic Regimes on the Body Mass, Behavioural and Stress Responses in Golden Mahseer, Tor putitora
}

\author{
Arun Kalkhundiya', Jyoti Chand ${ }^{1}$, Pankaj Kumar Bhatt ${ }^{1}$, Bipin Chandra Pathak ${ }^{*}$ and M. Serajuddin²
}

'Department of Zoology, L.S.M. Government P.G. College, Pithoragarh - 262501, Uttarakhand, India; arunkalkhundiya.05@gmail.com, jyotichand66@gmail.com,zoopth1963@gmail.com, bipinpathak11@gmail.com 2Department of Zoology, University of Lucknow, Lucknow-226007, Uttara Pradesh, India; lu.fisheries@gmail.com

\begin{abstract}
Golden mahseer, Tor putitora is a teleostean cold-water fish, known to occur in the rivers of Himalayas. Light affects the physiology of the fish. Therefore, the study was carried out to evaluate the effects of different photoperiodic regimes as environmental cues on the development of body mass, behavioural and stress responses in T. putitora. Fishes were exposed in the different photoperiodic regimes such as 8 hours light: 16 hours dark (8L:16D), 16 hours light 8 hours dark (16L:8D) and natural light condition. The body mass, cortisol and behavioural profiling were studied. Ethovision (XT-13) was used to record the different behavioural responses of the fish after the exposure to various photoperiodic regimes. The difference in the behavioural profiling and scoring was recorded in the different groups of the juveniles of the fish. Effects of light: dark skeletons such as 8 hours light: 16 hours dark (8L:16D), 16 hours light 8 hours dark (16L:8D) and natural light condition (Control) exhibited remarkable differences in the biomass enhancement in the juveniles of the fish $(\mathrm{P}<0.05)$. Maximum amount of cortisol $(0.93 \pm 0.08 \mathrm{ng} / \mathrm{ml})$ was recorded in the group of the fish exposed to $16 \mathrm{~L}: 8 \mathrm{D}$ compared to natural $(0.78 \pm$ $0.21 \mathrm{ng} / \mathrm{ml})$ and the group exposed to $8 \mathrm{~L}: 16 \mathrm{D}$ photoperiodic regime $(0.69 \pm 0.11 \mathrm{ng} / \mathrm{ml})$. A significant difference $(\mathrm{P}<0.05)$ in behavioural profiling of the fish exposed to green, red and natural colour was noticed, where velocity/swimming speed of the fish was most affected by the green light spectra. The significant difference in the behavioural profiling and scoring was recorded in the different groups of the juveniles of the fish.
\end{abstract}

Keywords: Behavioural, Cortisol, Golden Mahseer,Photoperiodic Skeleton

\section{Introduction}

Environmental cues affect the physiological governing in fish during the timing of reproduction, circannual rhythmicity as well as behavioural imprinting in the brain. Development of various stages of the fish is affected by environmental and nutritional factors. Growth of fish is affected by the feeding rate, feeds, water quality, stock density and size (Trzebiatowski et al., 1981, Kashyap et al., 2015) ${ }^{1,2}$. Photoperiod acts as a zeitgeber for the growth performance, maturation and behavioural imprinting in fish. The study on the effects of different photoperiodic regimes on the organismal physiology was carried out by various researchers in fish (Kashyap et al., 2015; Imsland, et al., 1995; SILVA-GARCIA, 1996; Purchase et al., 2000; Ruchin, 2004;
Rad et al., 2006; Taylor et al., 2006; Valenzuela et al., 2006; Bonnet et al., 2007; Askarian \& Kousha, 2009; Lee et al., $2019)^{2-12}$. Fiszbein et al. $(2010)^{13}$ studied the photoperiodic role to evaluate the behavioural profiling and reproductive events of the cichlid fish, Cichlasoma dimerus. El-Sayed and Kawanna (2004) ${ }^{14}$ have exposed the Oreochromis niloticus (Nile tilapia) fries to different conditions of the light regimes to study the specific growth rate, food conversion ratio, and weight gain and survival activity. Photoperiodic light intensities have been reported to play some roles in the enhancement of biomass and viability of juveniles of cultured Mexican cichlid fish, Cichlasoma beani (AragónFlores et al., 2017) ${ }^{15}$. Mustapha et al. $(2012)^{16}$ studied the role of light: dark cycle on the body pigments of the fry of Clarias gariepinus (African catfish). Growth and survival

*Author for correspondence 
of the juveniles of Indian major carps after the exposure of photoperiodic regimes were also studied by Kashyap et al. $(2015)^{2}$. Haematological and growth performances were affected by the photoperiodic manipulations in the juvenile of Rutilus rutilus caspicus (Shahkar et al., 2015) ${ }^{17}$. Maaswinkel et al. (2013) ${ }^{18}$ studied the shoaling behavioural responses in zebrafish after the exposure of alcohol. The different type of behavioural scoring of stress was studied in the zebrafish (Cachat et al., 2010) ${ }^{19}$. Lee et al. (2019) ${ }^{12}$ worked on the growth and behavioural aspect of zebrafish after the exposure of environmental signals. Some research workers reported that swimming nature has enhanced the biomass in fish through muscular growth and emphasized that the process of homeostasis provides immunity in relation to decreasing the confrontational behaviour (Davison, 1997; Palstra \& Planas, 2013) 20,21. Working on the coral reef fish breeding, Olivotto (Sarvi, 2012) ${ }^{22}$ reported that the variable light regime exposure affected the feed conversion efficiency which caused the changes in the development and behaviour parameters. Light penetration affects the biomass by enhancing the consumption rate of food, strengthening the muscular mass via increasing movement activity (Boeuf \& Le Bail, 1999) ${ }^{23}$. The effect of the variable light-dark cycle on the somatic growth and gonadal development (sexual maturity) has been studied by Rad et al. (2006) ${ }^{7}$ in Nile tilapia. An impact of photoperiodic events on the consumption rate of foodstuffs concerning to biomass and reproductive events physiology in the red-eyed, Poecilias phenops (molly) was worked by Zutshi and Singh (2017) ${ }^{24}$ during the artificial condition. The present study was carried out on the juveniles of hill stream Tor putitora (golden mahseer) which belongs to the family, Cyprinidae, is an inland water teleostean fish used as a middle feeder in pisciculture in the Himalayas foothills (Akhtar et al.,2017 $)^{25}$. T. putitora is confined in the south-east regions of the Himalayas (Nautiyal, 2014) ${ }^{26}$ where the fish inhabits in the running water of rivers (Bhatt \& Pandit, 2016 ${ }^{27}$. The population of the T. putitora is dwindling and belongs to the endangered category of IUCN. Therefore, the present scenario is demanding for the conservation of the fish. So, the present study was planned and carried out on the hypothesis that whether the photoperiodic events affect the development of biomass of juvenile fish and the impact of coloured lights on the behavioural patterning of the fish.

\section{Materials and Methods}

Juveniles of Tor putitora were collected from the River East Ramganga $\left(29.54^{\circ} \mathrm{N}, 80.104^{\prime} \mathrm{E}\right)$ in early morning hours, transported to the laboratory, acclimatized for environmental conditions of the aquarium, and experiment was carried out as per institutional ethics committee's guidelines. A total of 30 juveniles of T. putitora, weighing between $0.09-0.280 \mathrm{~g}$, were randomly selected and equally divided into three groups and kept in different aquaria $(60 \times 30 \times 30 \mathrm{~cm})$ namely A, B and C for 96 days. The water volume of 20 litres was maintained in each aquarium which was equipped with an aerator supported by an air cum filter water pump. A total of $20 \%$ of the water volume of each aquarium, excretory materials and other debris were removed daily and the water level was maintained according to the required volume. Fish of all groups were fed twice a day with the paste of liver of goat at the rate of $0.05 \mathrm{gm} /$ day throughout the experimental period. Each group of T. putitora was exposed to either of the below mentioned photoperiodic regimes:

(a) Short photoperiod (8L: 16D) of 8 hours light ( $\mathrm{L}^{\text {on }}$ at 8.00 am and $\mathrm{L}^{\text {off }}$ at $4.00 \mathrm{pm}$ )

(b) Long photoperiod (16L: 8D) of 16 hours light ( $\mathrm{L}^{\text {on }}$ at $4.00 \mathrm{pm}$ and $\mathrm{L}^{\text {off }}$ at $8.00 \mathrm{am}$ )

(c) Natural day length (12L: 12D)

Light-proof devices were used to separate the three different aquaria from each other, and artificial white fluorescent lamps of 5(W) LED (Panasonic), each was installed at a height of $10 \mathrm{~cm}$ above the water level of the aquarium. At the end of the experiment, all the juveniles of T. putitora were killed using clove oil as anaesthesia. The weight of each juvenile was recorded on an electronic balance sensitive up to 0.001 gm (Roy Electronics India, CBCAB300), and samples were immediately stored in $-20^{\circ} \mathrm{C}$. The whole body of juvenile fish was homogenised thrice in phosphate buffer saline (1X PBS) with the help of homogeniser (Remi) at $3500 \mathrm{rpm}$ for the complete extraction of cortisol. Yellowish supernatant was transferred into a tube (Eppendorf) and kept in $4^{\circ} \mathrm{C}$ for the evaporation of ether, and dissolved in 1X PBS buffer and kept at $4^{\circ} \mathrm{C}$ (Cachat et al., 2010). Enzyme-linked immunoassay (ELISA) was performed for the quantification of cortisol using a cortisol assay kit (Oxford Biomedical Research). The intensity of ELISA reactions was measured in the ELISA plate reader (Systronics) at $450 \mathrm{~nm}$.

\subsection{Effect of Colour Light on behaviour of Juvenile Fish}

In order to study the behavioural profiling of the fish exposed to green, red and natural colour, the 30 juveniles of T. putiora weighing between $0.22-0.30 \mathrm{~g}$ were divided into three groups in the three different aquaria $(60 \times 30 \times 30 \mathrm{~cm})$. The first group $(\mathrm{n}=10)$ was a natural control while others were green and red light exposed groups. Both groups were treated with the photoperiodic regime of $8 \mathrm{~L}: 16 \mathrm{D}$ ( $\mathrm{L}^{\text {on }}$ at 
8 a.m. and $L^{\text {off }}$ at 4 p.m.). Specific growth rate (SGR) was computed using the formula:

SGR\% $=100 \times$ (Final body weight-Initial body weight) $/$ time (days)

The number of live juveniles of each aquarium was recorded and expressed as a percentage of survival rates. A total of 12 individuals of T. putitora were selected for the behavioural study of $300 \mathrm{sec}$ at the rate of $25 \mathrm{frame} / \mathrm{sec}$. The behavioural status of the fish was analyzed using automated video-tracking software, Ethovision XT 13 (Noldus, Info Tech, Wageninen, Holland). The behavioural scoring such as total distance travelled (overall activity), angular velocity, turn angle, swimming speed or velocity, movement, and meander of the fish were studied and recorded.

\subsection{Statistical Analysis}

Statistical method such as one-way analysis of variance (ANOVA)followed by post-hoc test of Newman-Keuls Multiple Comparison was used to differentiate the various groups of the fish. All analysis was done using the graph pad prism (version 5) software.

\section{Results}

The final average body mass of juvenile fish exposed to natural (12L:12D), short (8L:16D) and long (16L:8D) photoperiodic regime recorded were $0.1490 \pm 0.006 \mathrm{~g}$, $0.1592 \pm 0.002 \mathrm{~g}$ and $0.1267 \pm 0.003 \mathrm{~g}$ respectively while the specific growth rate of the fish under natural, short and long photoperiodic regime was $16 \%, 15 \%$ and $12 \%$ respectively. One-way ANOVA analysis $\left(F_{2}, 15=13.80\right.$ at $\left.P<0.0004\right)$ followed by post-hoc test of Newman-Keuls Multiple Comparison showed a significant difference in the body mass of the juvenile fish of three groups (Figure 1).

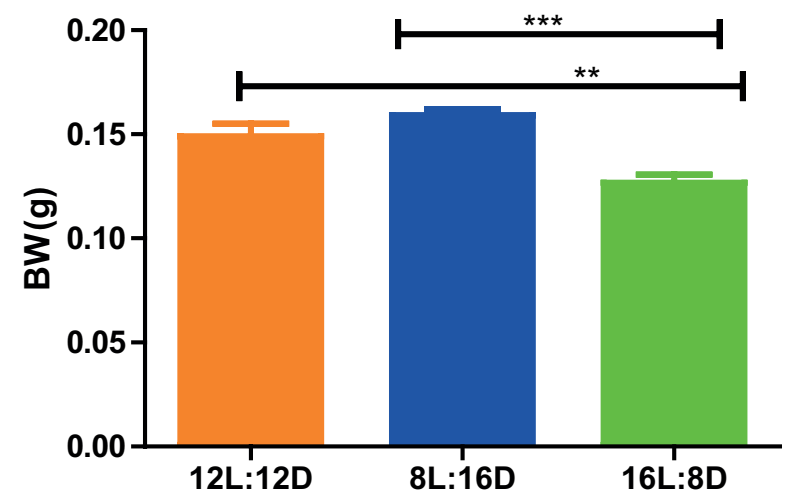

Figure 1. The final average body mass of juveniles of T. putitora.
The maximum mean value of cortisol hormone $(0.93 \pm 0.08 \mathrm{ng} / \mathrm{ml})$ was recorded in the fish exposed to long photoperiodic regime compared to that of short $(0.69 \pm 0.11 \mathrm{ng} / \mathrm{ml})$ and natural $(0.78 \pm 0.21 \mathrm{ng} / \mathrm{ml})$. However, no statistical difference was observed among the values of cortisol recorded among three groups of the fish (Figure 2).

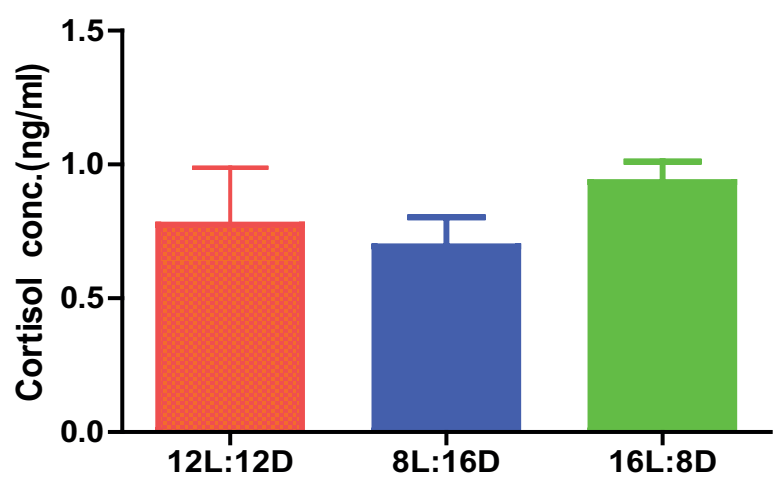

Figure 2. The average cortisol concentration in juveniles of T. putitora.

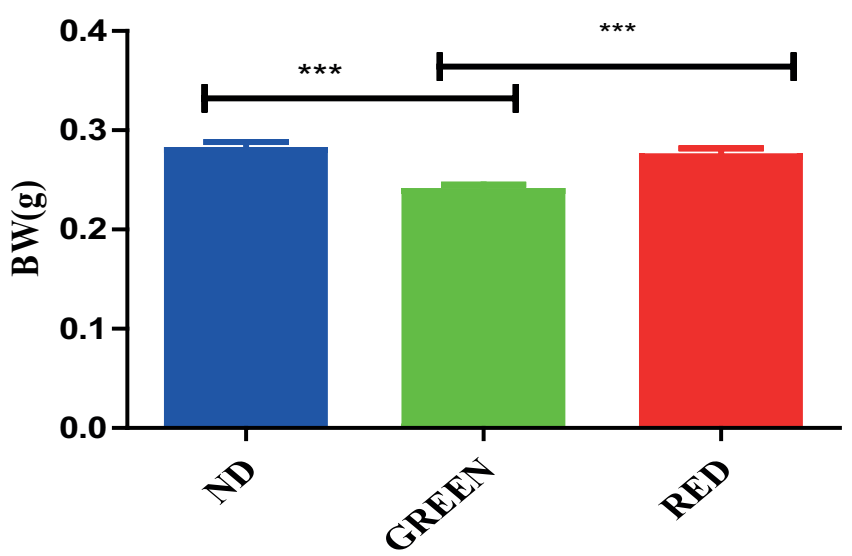

Figure 3. Body weight of juveniles after exposure to the different colour regimes.

The comparative average body mass of the juvenile fish exposed to natural photoperiod was higher $(0.28 \pm 0.008 \mathrm{~g})$ as compared to that of green $(0.24 \pm 0.006 \mathrm{~g})$ and red light $(0.27 \pm 0.008 \mathrm{~g})$ exposed fish for the short photoperiodic regime. Similarly, a high value of specific growth rate was noticed in the juvenile fish of natural group $(0.40 \pm 0.06 \% /$ day) as compared to that of green $(0.38 \pm 0.035 \% /$ day $)$ and red light $(0.34 \pm 0.07 \% /$ day $)$ exposed groups. The survival rate of juvenile fish was $100 \%$ in the group exposed to natural light while it was $90 \%$ in green and red lightexposed groups. One-way ANOVA analysis $\left(F_{2}, 14=16.09\right.$, 
$p<0.0001)$ followed by post hoc test of Newman-Keuls Multiple Comparison showed a significant difference among the values of the body mass of natural, green and red light-exposed groups at $P<0.05$ (Figure 3 ). The velocity or swimming speed of the juvenile fish recorded during the behavioural study were $32.04 \pm 1.12,36.00 \pm 1.68$ and 38.39 $\pm 0.54 \mathrm{~cm} / \mathrm{sec}$ in the fish exposed to natural, red and green lights respectively. The data of velocity was log-transformed for the normalization. The normalized data was subjected to one-way ANOVA analysis $\left(F_{2}, 2841=261.4\right.$ at $\left.P<0.0001\right)$. The post hoc Dunnett's multiple comparison test showed a significant difference among the values of the velocity of the fish exposed to natural, green and red lights at $\mathrm{P}<0.05$ (Figure 4). The maximum average distance was travelled by the fish exposed to green light $(7.68 \pm 0.11 \mathrm{~cm})$ compared to that of control $(6.41 \pm 0.22 \mathrm{~cm})$ and red light $(7.20 \pm 0.34 \mathrm{~cm})$ exposed groups during the trial observation of $300 \mathrm{sec}$. The data of travelled distance was log-transformed for the normalization. The normalized data was subjected to one-way ANOVA analysis $\left(F_{2}, 2841=261.7\right.$ at $\left.P<0.0001\right)$ by using the post-hoc Dunnett's Multiple Comparison test which showed a statistically significant difference at $P<0.05$ (Figure 5). The value of body elongation of the fish was $0.70 \pm 0.0064,0.75 \pm 0.003$ and $0.70 \pm 0.004$ in the juvenile fish exposed to natural, green and red light respectively which was significantly different from each other's at $\mathrm{P}<0.05$ (Figure 6). Maximum values of acceleration and meander were recorded in control and red groups respectively which were statistically significant $(\mathrm{P}<0.05)$. The details of acceleration and meander are given in (Figure 7 and 8).
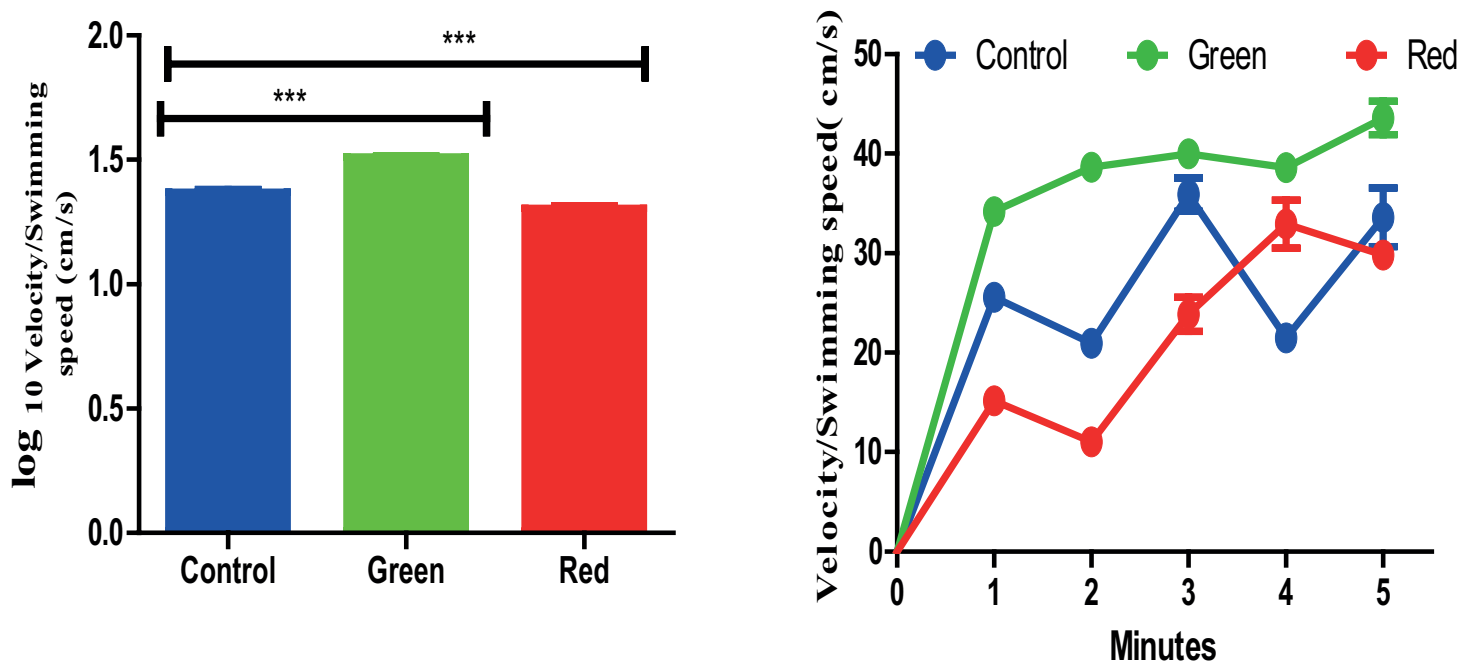

Figure 4. Velocity or swimming speed of the fish after exposure to the different colour regimes.
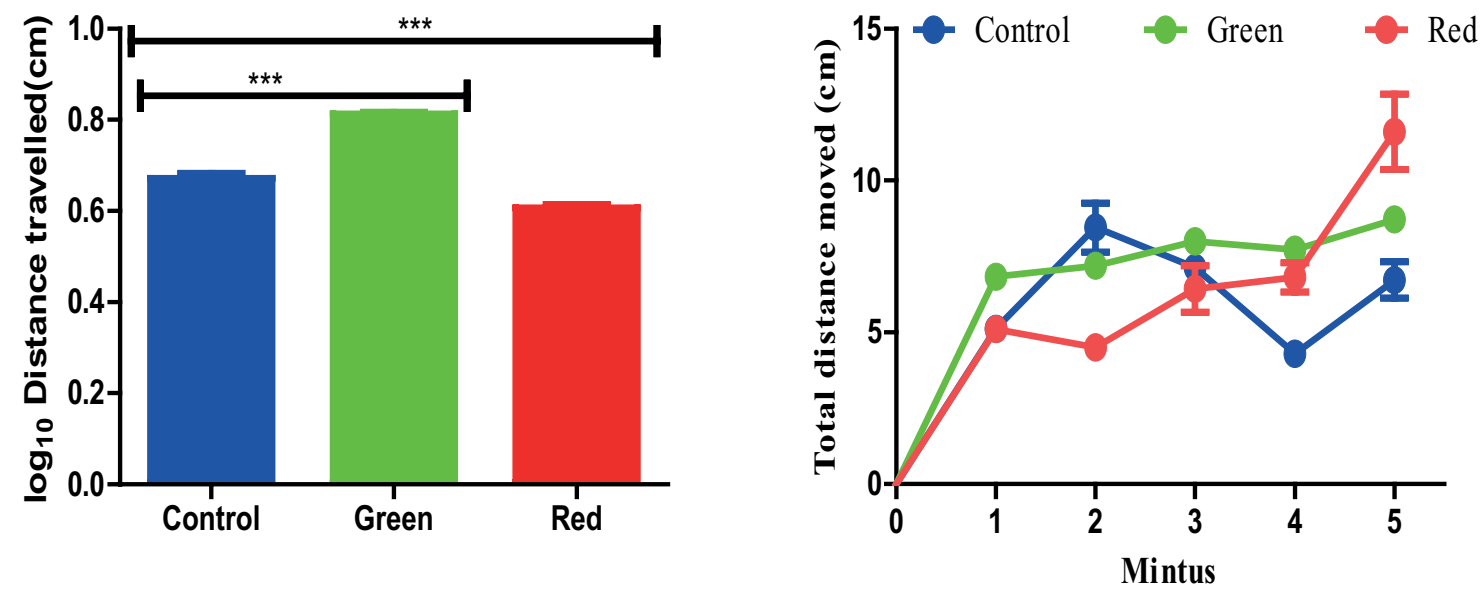

Figure 5. The average distance travelled by fish during the trial observation. 

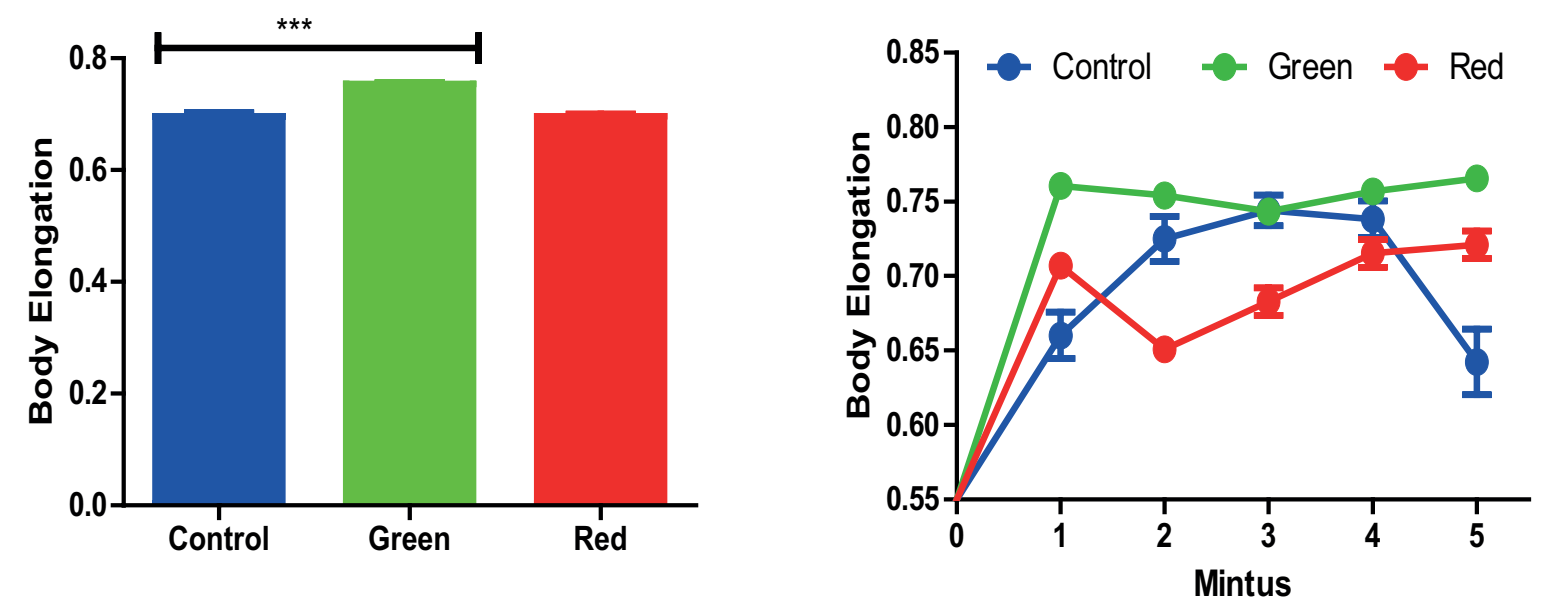

Figure 6. Body elongation of the fish during the observational scaling.

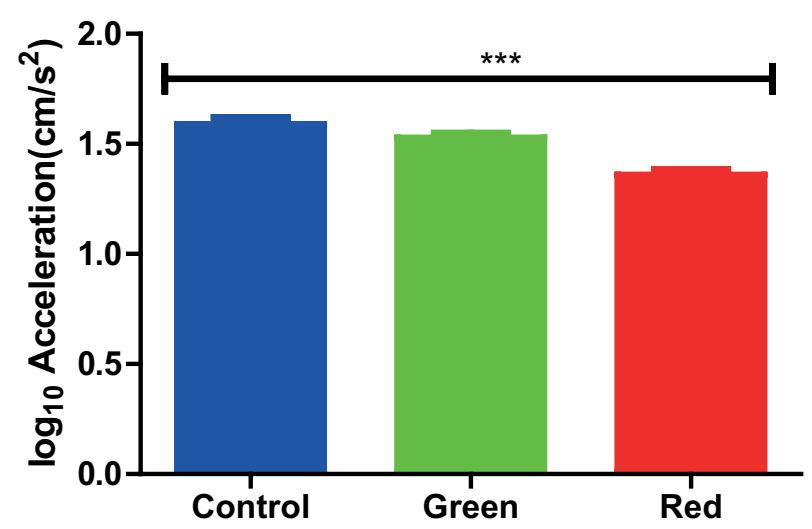

Figure 7. Acceleration of fish during the behavioural observation.
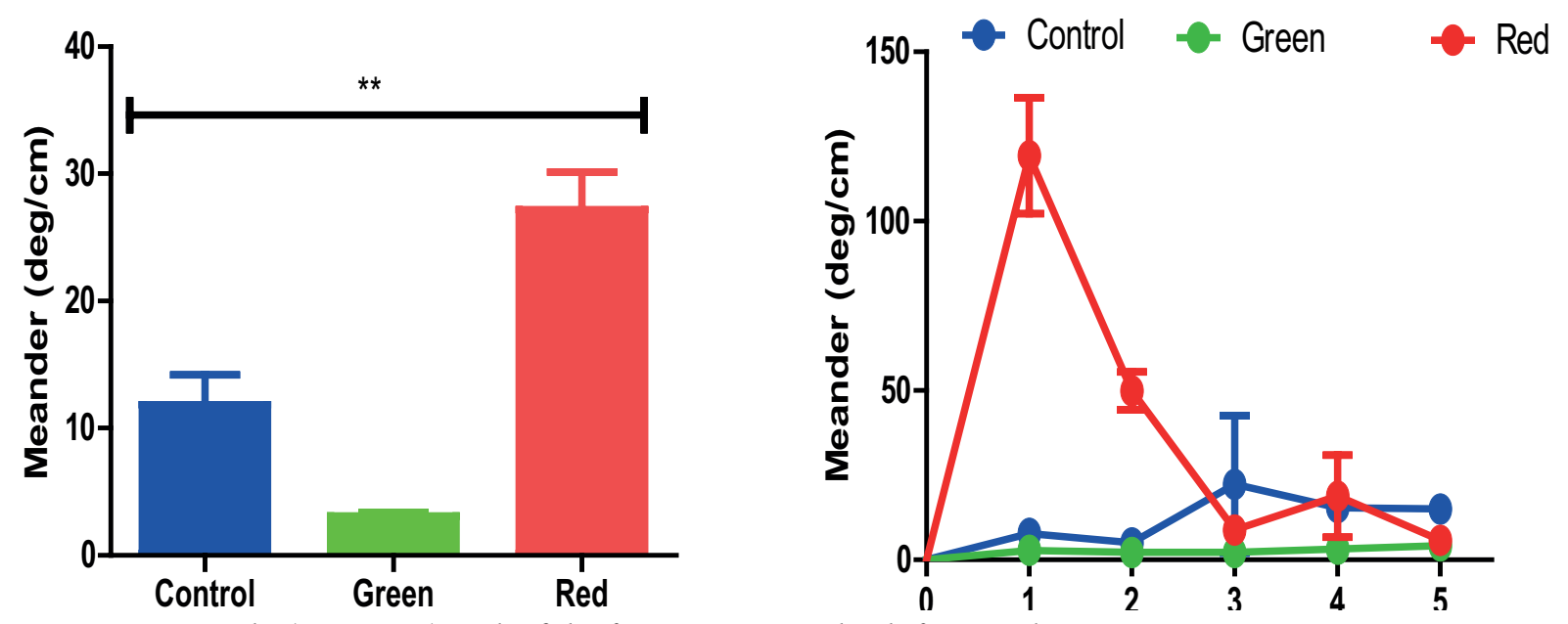

Figure 8. Meander(Mean \pm SE) in the fish after exposure to the different colour regimes. 


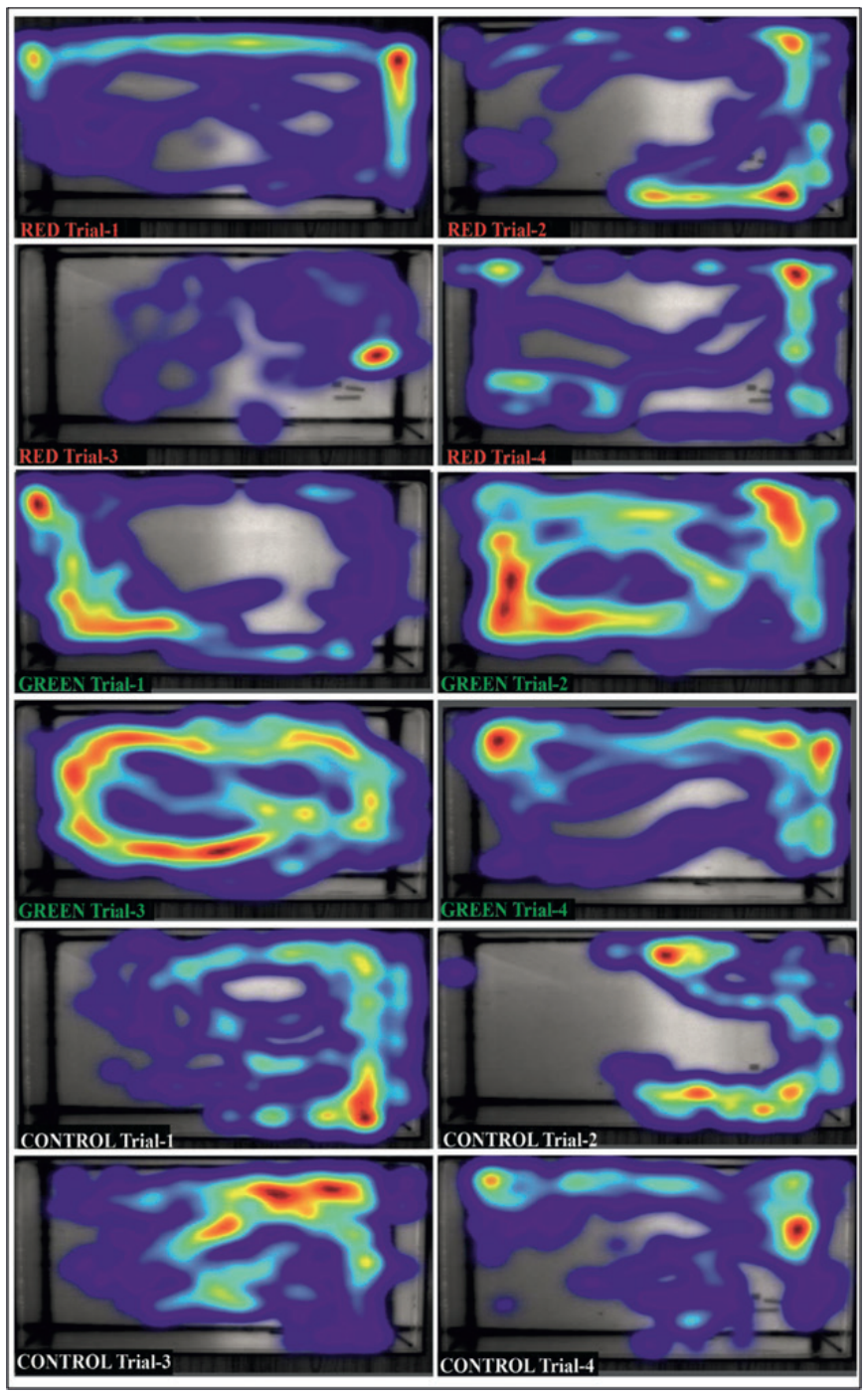

Figure 9. Heat map of activity pattern of the juveniles of T. putitora.

\section{Discussion}

Requirement of photoperiod is an extremely variable factor in fish which is related to adaptation to environmental conditions, and specific to species and age (SILVA-GARCIA, 2020; Boeuf $\&$ Le Bail 1999) $)^{4,23}$. The present findings showed that the juvenile growth of $T$. putitora is affected by the treatments of various photoperiodic regimes; and short day light (8L:16D) was found to be suitable for the growth of the fish. Similarly, Arvedlund et al. (2000) $)^{28}$ also reported slow growth under continuous light (24L:0D) compared to 16L:8D in Amphiprion melanopus. A number of researchers (Fuchs, 1978; BarahonaFernandes, 1979; Barlow et al., 1995) ${ }^{29-31}$ reported different optimum photoperiodic regimes for different fish species. In contrast to the present findings, the growth performance of the juveniles of Caspian roach, Rutilus rutilus caspicus was maximum in the $24 \mathrm{~h}$ light exposure as compared to another photoperiodic skeleton (Shahkar et al., 2015) ${ }^{17}$.
The cortisol concentration was highest in the juvenile fish exposed to $16 \mathrm{~L}: 8 \mathrm{D}$ photoperiodic regime in the present study as compared to other photoperiodic regimes. Pavlidis et al. $(1992)^{32}$ had worked on the common Dentex dentex (Dentax) and also reported the highest value of cortisol in the fish exposed to 16L:8D photoperiodic regime. Audet et al. (1986) $)^{33}$ working on Gasterosteus aculeatus, reported and emphasized that the level of cortisol remains high in the fish exposed to the short photoperiodic regime.Light differentiated into six distinct spectra $(\mathrm{V}, \mathrm{B}, \mathrm{G}, \mathrm{Y}, \mathrm{O}, \mathrm{R})$ in decreasing wavelength (Singh, 2006; Heydarnejad et al., 2017) ${ }^{34,35}$. Different light spectra act as environmental cues and affect the growth and reproduction and coordinate the different stages of life in

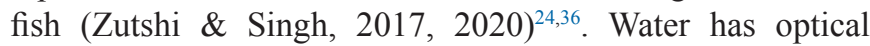
properties which lead to the different light-absorbing pattern at different degrees. Psychologists reported that the different colour spectra show different properties of warm and cool in their nature, which affect the brain through absorbance of wavelength. Red and orange are warmer while the blue and green are relatively cool. Fujii $(2000)^{37}$ has emphasised that the intensity of light regulates the chromatophore activity in fishes because of aggregation or dispersion of pigments, Effect of different colours of the artificial light on the growth of juveniles of common carp (Cyprinus carpio) showed that the red light gives better growth performance as compared to blue, white, yellow, green and dark (Abdul-Nabi Nasir $\&$ Willaim Farmer, 2017) $)^{38}$. In the present study, a high growth was recorded in the juveniles fish exposed to red light compared to green colour exposed groups. The movement tracking analysis to quantify the behavioural changes in the fish in every $0.20 \mathrm{sec}$ was carried out of using Ethovision (XT 13) where swimming speed, distance travelled elongation and meander (turning movement) were recorded in order to study their effects on the growth of the fish. Fish species have their own daily cycle of activities based on the endocrine signalling, maturation and behavioural status. Most of the animals including fish are having light-sensitive circadian clocks which provide internal synchronization by regulating melatonin, known as time-keeping hormone that affects the rhythmic physiological functions of fish (Bromage et al., 2001; Villamizar et al., 2009) ${ }^{39,40}$.The behaviours are affected by colour lights in fish which are species-specific (Villamizar et al., 2009; Volpato et al., 2013; Villamizar et al., 2011 $)^{40-42}$. The scoring of behavioural parameters such as velocity or swimming speed, travelling distance, body elongation, acceleration and meander were carried out for the first time in the juveniles of T. putitora for the quantification of their behavioural profiling after the exposure of different light spectra. In our study, swimming speed, distance travelling and body elongation were maximum in the group of fish exposed to green light compared to that of natural and red light exposed groups, which indicated that the rate of exploration was supported by green light in the fish. Measuring behavioural, the different activity pattern was showed in heat maps (Figure 9). Endocrine responses and neuro-phenotyping studies were 
carried out by Cachat et al. $(2010,2011)^{19,43}$ in adult zebrafish where they studied the body elongation pattern as well as 3D swimming trajectory. The sensitivity of Zebrafish towards the spectra was also carried out by Stewart (Stewart et al., 2015) (4 $^{44}$ where meander in the group of fish exposed to red light was higher as compared to others indicating that the fish made more trajectories for themselves for the capturing of food because of the impact of light on the brain of the fish. The information on the function of the clock and light-sensitive neuron within the brain, till to this date, is unknown in T. putitora. Therefore, additional studies are required for understating the impacts of colours for generating effective signals which change the fish behavioural activity by conveying the message to the brain.

\section{Conclusion}

Photoperiodic regime of short day is effective for growth enhancements in the juveniles of T. putitora. The coloured lights affect the behavioural changes in the fish.

\section{Acknowledgements}

The authors are thankful to the Principal for providing the facility, and Department of Science \& Technology (DST) Govt. of India for the financial support under the Young Scientist Scheme (YSS/2015/000538).

\section{Conflict of Interest}

There is no conflict of interest among the authors.

\section{References}

1. Trzebiatowski R, Filipiak J, Jakubowski R. Effect of stock density on growth and survival of rainbow trout (Salmo gairdneri Rich.). Aquaculture. 1981; 22(C):289295. https://doi.org/10.1016/0044-8486(81)90155-1.

2. Kashyap A, Chandra Pathak B, Awasthi M, Serajuddin M. Effect of different photoperiods on the growth and survival of juvenile of Indian major carp, Catla catla. Iran J Fish Sci. 2015; 14(4):946-955.

3. Imsland AK, Folkvord A, Stefansson SO. Growth, oxygen consumption and activity of juvenile turbot (Scophthalmus Maximus L.) reared under different temperatures and photoperiods. Netherlands J Sea Res. 1995; 34(1-3):149-159. https://doi.org/10.1016/00777579(95)90023-3.

4. SILVA-GARCIA, AJ. Growth of juvenile gilthead seabream (Sparus aurata L.) reared under different photoperiod regimes. Isr J Aquacult Bamidgeh [Internet]. 1996 [cited 2020 Oct 12]; 48:84-93. Available from: http://ci.nii.ac.jp/naid/10018292099/en/.
5. Purchase CF, Boyce DL, Brown JA. Growth and survival of juvenile yellowtail - ounder Pleuronectes ferrugineus (Storer) under different photoperiods. Aquac Res. 2000; 31:547-552. https://doi.org/10.1046/ j.1365-2109.2000.00480.x.

6. Ruchin $\mathrm{AB}$. Influence of colored light on growth rate of juveniles of fish. Fish Physiol Biochem. 2004; 30(2):175178. https://doi.org/10.1007/s10695-005-1263-4.

7. Rad F, Bozaoglu S, Ergene Gözükara S, Karahan A, Kurt G. Effects of different long-day photoperiods on somatic growth and gonadal development in Nile tilapia (Oreochromis niloticus L.). Aquaculture. 2006; 255(14):292-300. https://doi.org/10.1016/j.aquaculture.2005. 11.028 .

8. Taylor JF, North BP, Porter MJR, Bromage NR, Migaud $\mathrm{H}$. Photoperiod can be used to enhance growth and improve feeding efficiency in farmed rainbow trout, Oncorhynchus mykiss. Aquaculture. 2006; 256(14):216-234. https://doi.org/10.1016/j.aquaculture.2006. 02.027 .

9. Valenzuela AE, Silva VM, Klempau AE. Qualitative and quantitative effects of constant light photoperiod on rainbow trout (Oncorhynchus mykiss) peripheral blood erythrocytes. Aquaculture. 2006; 251(2-4):596602. https://doi.org/10.1016/j.aquaculture.2005.06.012.

10. Bonnet E, Montfort J, Esquerre D, Hugot K, Fostier A, Bobe J. Effect of photoperiod manipulation on rainbow trout (Oncorhynchus mykiss) egg quality: A genomic study. Aquaculture. 2007; 268(1-4 SPEC. ISS.):13-22. https://doi.org/10.1016/j.aquaculture.2007.04.027.

11. Askarian F, Kousha A. The influence of photoperoid in farming Beluga sturgeon (Huso huso): Evaluation by growth and health parameters in serum. J Fish Aquat Sci. 2009; 4(1):41-49. https://doi.org/10.3923/jfas.2009. 41.49 .

12. Lee CJ, Paull GC, Tyler CR. Effects of environmental enrichment on survivorship, growth, sex ratio and behaviour in laboratory maintained zebrafish Danio rerio. J Fish Biol. 2019; 94(1):86-95. https://doi.org/ 10.1111/jfb.13865. PMid:30443966.

13. Fiszbein A, Cánepa M, Vázquez GR, Maggese C, Pandolfi M. Photoperiodic modulation of reproductive physiology and behaviour in the cichlid fish Cichlasoma dimerus. Physiol Behav. 2010; 99(4):425-432.https://doi. org/10.1016/j.physbeh.2009.11.017. PMid:20045426.

14. El-Sayed AFM, Kawanna M. Effects of photoperiod on the performance of farmed Nile tilapia Oreochromis niloticus: I. Growth, feedutilization efficiency and survival 
of fry and fingerlings. Aquaculture. 2004; 231(1-4):393402. https://doi.org/10.1016/j.aquaculture.2003.11.012.

15. Aragón-Flores EA, Martínez-Cárdenas L, HernándezGonzález C, Barba-Quintero G, Zavala-Leal OI, Ruiz-Velazco JM, et al. Effect of light intensity and photoperiod on growth and survival of the Mexican cichlid, Cichlasoma beani in culture conditions. Lat Am J Aquat Res. 2017; 45(2):293-301. https://doi. org/10.3856/vol45-issue2-fulltext-5.

16. Mustapha MK, Okafor BU, Olaoti KS, Oyelakin OK. Effects of three different photoperiods on the growth and body coloration of juvenile African catfish, Clarias gariepinus (Burchell). Arch Polish Fish. 2012; 20(1):5559. https://doi.org/10.2478/v10086-012-0007-1.

17. Shahkar E, Kim DJ, Mohseni M, Khara H, Yun H, Bai SC. Effects of photoperiod manipulation on growth performance and hematological responses of juvenile caspian roach Rutilus rutilus caspicus. Fish Aquat Sci. 2015; 18(1):51-56. https://doi.org/10.5657/ FAS.2015.0051.

18. Maaswinkel H, Le X, He L, Zhu L, Weng W. Dissociating the effects of habituation, black walls, buspirone and ethanol on anxiety-like behavioral responses in shoaling zebrafish. A 3D approach to social behavior. Pharmacol Biochem Behav. 2013; 108:16-27. https:// doi.org/10.1016/j.pbb.2013.04.009. PMid:23603028.

19. Cachat J, Stewart A, Grossman L, Gaikwad S, Kadri F, Chung KM, et al. Measuring behavioral and endocrine responses to novelty stress in adult zebrafish. Nat Protoc [Internet]. 2010; 5(11):1786-99. Available from: http://dx.doi.org/10.1038/nprot.2010.140 https://doi. org/10.1038/nprot.2010.140. PMid:21030954.

20. Davison W. The effects of exercise training on teleost fish, a review of recent literature. Comp Biochem Physiol - A Physiol. 1997; 117(1):67-75. https://doi. org/10.1016/S0300-9629(96)00284-8.

21. Palstra AP, Planas JV. Swimming physiology of fish: Towards using exercise to farm a fit fish in sustainable aquaculture. Swim Physiol Fish Towar Using Exerc to Farm a Fit Fish Sustain Aquac. 2013; 1-429. https://doi. org/10.1007/978-3-642-31049-2.

22. Sarvi B. Breeding and rearing of Amphiprion clarkii in a commercial scale. 2012; (April).

23. Boeuf G, Le Bail PY. Does light have an influence on fish growth? Aquaculture. 1999; 177(1-4):129-152. https://doi.org/10.1016/S0044-8486(99)00074-5.

24. Zutshi B, Singh A. Impact of Photoperiod as an Environmental Cue on Growth and Reproductive Performance in the Red Eyed Orange Molly (Poecilia sphenops). Proc Zool Soc. 2020; 73(1):25-31. https:// doi.org/10.1007/s12595-019-00294-6.

25. Akhtar MS, Ciji A, Sarma D, Rajesh M, Kamalam BS, Sharma P, et al. Reproductive dysfunction in females of endangered golden mahseer (Tor putitora) in captivity. Anim Reprod Sci [Internet]. 2017; 182:95-103. Available from: https://doi.org/10.1016/j. anireprosci.2017.05.004. PMid:28545985.

26. Nautiyal P. Erratum: Review of the art and science of Indian mahseer (Game Fish) from nineteenth to twentieth century: Road to extinction or conservation? (Proc. Natl. Acad. Sci., India, Sect. B Biol. Sci DOI: 10.1007/s40011-013-0233-3). Proc Natl Acad Sci India Sect B - Biol Sci. 2014; 84(2):237. https://doi. org/10.1007/s40011-014-0317-8.

27. Bhatt JP, Pandit MK. Endangered Golden mahseer Tor putitora Hamilton: A review of natural history. Rev Fish Biol Fish. 2016; 26(1):25-38. https://doi.org/10.1007/ s11160-015-9409-7.

28. Arvedlund M, MIM and Abstract TA. Effects of photoperiod on growth of larvae and juveniles of the anemonefish Amphiprion melanopus. Aquac Res. 2000; 23(2):18-23.

29. Fuchs J. Influence de la photoperiode sur la croissance et la survie de la larve et du juvenile de sole (Solea solea) en elevage. Aquaculture. 1978;15(1):63-74. https://doi. org/10.1016/0044-8486(78)90072-78.

30. Barahona-Fernandes MH. Some effects of light intensity and photoperiod on the sea bass larvae (Dicentrarchus labrax (L.)) reared at the Centre Oceanologique de Bretagne. Aquaculture. 1979; 17(4):311-321. https:// doi.org/10.1016/0044-8486(79)90086-3.

31. Barlow CG, Pearce MG, Rodgers LJ, Clayton P. Effects of photoperiod on growth, survival and feeding periodicity of larval and juvenile barramundi Lates calcarifer (Bloch). Aquaculture. 1995; 138(1-4):159168. https://doi.org/10.1016/0044-8486(95)01073-4.

32. Pavlidis M, Greenwood L, Paalavuo M, Mölsä H, Laitinen JT. The effect of photoperiod on diel rhythms in serum melatonin, cortisol, glucose, and electrolytes in the common dentex, Dentex dentex. Gen Comp Endocrinol. 1999; 113(2):240-250. https://doi. org/10.1006/gcen.1998.7190. PMid:10082626.

33. Audet C, FitzGerald GJ, Guderley H. Photoperiod effects on plasma cortisol levels in Gasterosteus aculeatus. Gen Comp Endocrinol. 1986; 61(1):76-81. https://doi.org/10.1016/0016-6480(86)90251-0. 
34. Singh S. Impact of color on marketing. Manag Decis. 2006; 44(6):783-789. https://doi.org/10.1108/ 00251740610673332.

35. Heydarnejad MS, Fattollahi M, Khoshkam M. Influence of light colours on growth and stress response of pearl gourami Trichopodus leerii under laboratory conditions. J Ichthyol. 2017; 57(6):908-912. https://doi. org/10.1134/S0032945217060054.

36. Zutshi B, Singh A. Interrelationship of photoperiod and feed utilization on growth and reproductive performance in the Red eyed orange molly (Poecilia sphenops). 2017; 209-346. https://doi.org/10.1101/20 9346.

37. Fujii R. The regulation of motile activity in fish chromatophores. PigmentCell Res.2000;13(5):300-319. https://doi.org/10.1034/j.1600-0749.2000.130502.x. PMid:11041206.

38. Abdul-Nabi Nasir N, Willaim Farmer K. Effects of different artificial light colors on the growth of juveniles common carp (Cyprinus carpio). Mesopo Environ J [Internet]. 2017;3(3):79-86. Available from: www. bumej.com.

39. Bromage N, Porter M, Randall C. The environmental regulation of maturation in farmed finfish with special reference to the role of photoperiod and melatonin. Aquaculture. 2001;197(1-4):63-98. https://doi.org/10.1 016/S0044-8486(01)00583-X.
40. Villamizar N, Blanco-Vives B, Migaud H, Davie A, Carboni S, Sánchez-Vázquez FJ. Effects of light during early larval development of some aquacultured teleosts: A review. Aquaculture [Internet]. 2011; 315(1-2):8694. Available from: https://doi.org/10.1016/j.aquacul ture.2010.10.036.

41. Volpato GL, Bovi TS, de Freitas RHA, da Silva DF, Delicio HC, Giaquinto PC, et al. Red Light Stimulates Feeding Motivation in Fish but Does Not Improve Growth. PLoS One. 2013; 8(3):1-5. https://doi.org/10.1371/journal. pone.0059134. PMid: 23516606 PMCid:PMC3597620.

42. Villamizar N, García-Alcazar A, Sánchez-Vázquez FJ. Effect of light spectrum and photoperiod on the growth, development and survival of European sea bass (Dicentrarchus labrax) larvae. Aquaculture [Internet]. 2009; 292(1-2):80-86. Available from: https://doi.org/ 10.1016/j.aquaculture.2009.03.045.

43. Cachat J, Stewart A, Utterback E, Hart P, Gaikwad S, Wong K, et al. Three-dimensional neurophenotyping of adult zebrafish behavior. PLoS One. 2011;6(3). https://doi.org/10.1371/journal.pone.0017597. PMid:21408171 PMCid:PMC3049776.

44. Stewart AM, Grieco F, Tegelenbosch RAJ, Kyzar EJ, Nguyen M, Kaluyeva A, et al. A novel 3D method of locomotor analysis in adult zebrafish: Implications for automated detection of CNS drug-evoked phenotypes. J Neurosci Methods. 2015;255 (January):66-74. Available from: https://doi.org/10.1016/j.jneumeth.2015.07.023. PMid:26238728. 